\title{
Originals
}

\section{Hypoglycaemic brain damage: effect of a dihydropyridine calcium channel antagonist in rats}

\author{
R. N. Auer ${ }^{1}$, L. G. Anderson ${ }^{2}$ \\ ${ }^{1}$ Department of Pathology, University of Calgary, Calgary, Alberta, Canada \\ ${ }^{2}$ Department of Pharmacology and Therapeutics, University of Calgary, Calgary, Alberta, Canada
}

Summary Hypoglycaemic brain damage consists of selective necrosis of cerebral neurons related to the extracellular release of excitatory amino acids. Neuronal excitatory amino acid receptors are activated and calcium channels are opened. The present investigation was designed to test the effectiveness of dihydropyridine blockade of voltage-sensitive calcium channels in hypoglycaemic brain damage. Sixty-four rats were given either high-dose nimodipine, consisting of an initial bolus of $300 \mu \mathrm{g} / \mathrm{kg}$ nimodipine administered at the stage of EEG slowing (blood glucose levels of $1.0-1.5 \mathrm{mmol} / \mathrm{l}$ ), followed by continuous intravenous nimodipine infusion at $1.5 \mu \mathrm{g} \cdot \mathrm{kg}^{-1}$. $\min ^{-1}$, low-dose nimodipine, consisting of an initial bolus of $30 \mu \mathrm{g} / \mathrm{kg}$ at the time of EEG slowing, fol- lowed by $0.15 \mu \mathrm{g} \cdot \mathrm{kg}^{-1} \cdot \mathrm{min}^{-1}$, an equal volume of vehicle solution, or $154 \mathrm{mmol} / 1 \mathrm{NaCl}$. Animals receiving either low- or high-dose nimodipine had higher mortality, and increased brain damage compared with controls. Examination of the perfusion-fixed brains 1 week after recovery with glucose revealed that quantitated neuronal necrosis was worsened by nimodipine in the hippocampus, caudate nucleus and cerebral cortex. The present results in profound hypoglycaemia (accompanied by a flat EEG) contrast with the beneficial effect of nimodipine in brain ischaemia. [Diabetologia (1996) 39: 129-134]

Key words Hypoglycaemia, brain damage, neuronal necrosis, channel antagonist, dihydropyridine.
Severe hypoglycaemia is most commonly seen in association with the treatment of diabetes, and intensive insulin therapy may increase its frequency [1]. The interaction of hypoglycaemia severe enough to cause brain damage with voltage-sensitive calcium channel (VSCC) antagonists has not been well studied, although diabetic patients might be taking such drugs for treatment of hypertension $[2,3]$ or diabetic neuropathy [4].

The pathophysiology of hypoglycaemic brain damage, like that of ischaemic brain damage involves the

Received: 19 April 1995 and in revised form: 30 June 1995

Corresponding author: Dr. R.N. Auer, Department of Pathology, University of Calgary, 3330 Hospital Drive N. W., Calgary, Alberta, T2N 4N1 Canada

Abbreviations: EAA, Excitatory amino acid; NMDA, N-methyl-D-aspartate; VSCC, voltage-sensitive calcium channels; ANOVA, analysis of variance. release of excitatory amino acids (EAA) into the extracellular space of the brain. During hypoglycaemia, microdialysis experiments have shown that the predominant amino acid released is metabolically derived aspartate, which increases 16 -fold in the dialysate [5]. There is a lesser increase in interstitial fluid levels of glutamate [5]. Both aspartate and glutamate are capable of activating various subtypes of EAA receptors, including N-methyl-D-aspartate (NMDA) receptors. During hypoglycaemia, blockade of NMDA receptors has been shown to reduce both the efflux of EAAs from brain cells [6] and neuronal necrosis in several major brain regions, including the striatum, CA1 zone and dentate gyrus of the hippocampus [7, 8]. Necrosis of nerve cells in the striatum, and in both CA1 and the dentate gyrus of the hippocampus, can be seen in human hypoglycaemic brain damage [9-11].

The demonstration that NMDA receptor antagonists can ameliorate hypoglycaemic brain damage 
may support the calcium hypothesis of neuronal necrosis, since NMDA-gated channels are permeable to calcium. However, neurons can be depolarized by the activation of receptors other than those of the NMDA subtype and depolarization from any cause will open voltage-gated calcium channels. In ischaemia, blockade of the VSCCs using drugs such as flunarizine [12] or nimodipine [13-15] has been shown to decrease neuronal necrosis.

The calcium channel antagonists nimodipine and verapamil have also been shown to mitigate ischaemia-associated acidosis [16] a process due to excessive glycolytic flux and hydrogen ion production. In contrast to ischaemic brain damage, hypoglycaemic brain damage cannot generate an intraparenchymal acidosis. There are several other important pathophysiologic differences between hypoglycaemia and ischaemia [17] and in view of these, it seemed justified to study the effects of nimodipine on hypoglycaemic brain damage using quantitative neuropathologic techniques. The recent introduction of nimodipine into clinical use for the treatment of aneurysmal subarachnoid haemorrhage, [18] and the emerging use of nifedipine to treat hypertension in diabetic patients $[2,3]$ gave further impetus to study a dihydropyridine calcium blocker in pathophysiologic situations other than ischaemia. We tested the hypothesis that nimodipine could alter brain damage due to profound hypoglycaemia of a depth and duration that would be clinically accompanied by coma.

\section{Materials and methods}

The hypoglycaemic model used has been described previously in detail [19]. Briefly, 64 male Wistar rats, weighing 253-367 g, were used. The animals were allowed access to normal rat chow and water ad libitum but were fasted overnight before the experiments. The next morning, insulin $(6 \mathrm{IU} / \mathrm{kg})$ was given i.p. $40 \mathrm{~min}$ before surgery. The rats were then anaesthetized with $4 \%$ halothane, intubated, and maintained on $1 \%$ halothane in a $2: 1 \mathrm{~N}_{2} \mathrm{O}: \mathrm{O}_{2}$ mixture. A lateral tail vein and the tail artery were cannulated. A jugular venous catheter was inserted for blood pressure control via exsanguination and reinfusion of blood as necessary. Bipolar subcutaneous leads were used to record the EEG. Temporalis muscle and rectal temperature probes were inserted, and the core temperature was regulated to $37.0-37.5^{\circ} \mathrm{C}$ by the use of a servo-controlled homeothermic bianket system. Temporalis temperature was found to follow core temperature, being $1.5-2.0^{\circ} \mathrm{C}$ cooler, and did not fall during hypoglycaemia. Since the brain receives normal to increased perfusion during hypoglycaemia [20], no attempt was made to separately regulate head temperature. The mean arterial blood pressure was recorded to computer disk automatically every $5 \mathrm{~s}$. Blood glucose levels were monitored using glucose oxidase reagent strips, and serial changes in the EEG were also observed and recorded. The period of electrocerebral silence (isoelectric EEG) was used to determine the duration of profound hypoglycaemia since this, not the absolute level of very low blood glucose levels is the determinant of the severity of the insult [19].
Once the EEG went flat, blood was drawn as necessary into a pre-warmed, heparinized syringe in order to control sympathetically mediated blood pressure increases above $160 \mathrm{~mm} \mathrm{Hg}$. After $30 \mathrm{~min}$ of EEG silence, the rats were recovered with an i.v. injection of $1 \mathrm{ml}$ of $25 \%$ glucose, and blood glucose levels were measured between 30 min to $1 \mathrm{~h}$ later. As the rats regained consciousness, they were extubated, after which they were returned to their cages and allowed to survive for 7 days.

Nimodipine (1,4-dihydro-2, 6-dimethyl-4-(3-nitrophenyl)3,5-pyridine dicarboxylic dicarboxylic acid 2-methoxyethyl 1methylethyl ester, mol. wt. 418.5) and its vehicle, containing polyethylene glycol and alcohol, were obtained from Miles Pharmaceuticals, West Haven, Conn., USA. In order to maximize the potential for determining a drug effect, treatment was begun prior to the onset of hypoglycaemia-induced electrical silence, during the period of high amplitude delta $(\delta)$ wave EEG activity in the range of $1-4 \mathrm{~Hz}$. No cellular damage is incurred at this stage of hypoglycaemia [19]. Two treated groups (low-dose and high-dose nimodipine) and two control groups (vehicle and saline) were studied. The low-dose and high-dose treated groups received, respectively, a $2 \mathrm{mg} / \mathrm{ml}$ or $20 \mathrm{mg} / \mathrm{ml}$ solution of nimodipine, at a rate of $0.15 \mu \mathrm{g} \cdot \mathrm{kg}^{-1} \cdot \mathrm{min}^{-t}$ or $1.5 \mu \mathrm{g} \cdot \mathrm{kg}^{-1} \cdot \mathrm{min}^{-1}$, after an initial nimodipine bolus of $30 \mu \mathrm{g} /$ $\mathrm{kg}$ or $300 \mu \mathrm{g} / \mathrm{kg}$, given slowly by hand over several min. Since nimodipine is light sensitive, the syringe containing the nimodipine, and the intravenous tubing were wrapped in aluminum foil. Two control groups were studied, each receiving identical volumes and rates of fluid injection as the treated animals. The first control group received a continuous infusion of $154 \mathrm{mmol} / 1 \mathrm{NaCl}$ (saline group), and the second control group received the nimodipine vehicle (ethanol and polyethylene glycol). The nimodipine and control infusions in all three groups were continued for $24 \mathrm{~h}$.

Previous study of the time course of cellular changes during hypoglycaemia revealed that the acidophilic neurons seen at 1 week are necrotic, and are subsequently removed from the tissue [21]. Thus, 1 week was chosen as the survival period. At the end of 1 week, rats from all four groups were re-anaesthetized and re-intubated. Under $2 \%$ halothane, a thoracotomy was done, and the brain was perfused via the introduction of $4 \%$ phosphate-buffered formaldehyde into the ascending aorta. The brains were removed from the skull the following day. After processing and embedding in paraffin, $8-\mu \mathrm{m}$ sections were double stained with $0.1 \%$ cresyl violet and $2 \%$ phloxine.

Because memory deficits are extremely sensitive to neuronal loss in the hippocampus [22], special attention was directed to quantitating cell loss in that region. Subserial sections of the entire rat brain were performed in order to visualize the hippocampus at seven standardized coronal levels. This allowed the dentate gyrus and CA1 sector to be quantitated for neuronal necrosis along the entire septo-temporal axis of the hippocampus (Fig. 1). In the dentate gyrus after bypoglycaemia, a geographic area of necrosis involves the crest of the gyrus [23] and external blade (Fig. 2a). Using image analysis, the area of this contiguous band of necrotic cells was measured, and divided by the total area of the dentate (Fig. $2 \mathrm{~b}$ ). This was performed at eight standardized coronal levels (Fig. 1), and total dentate necrosis (Fig. $3 \mathrm{a}$ ) was obtained by dividing the total traced area of necrotic dentate granule cells by the total measured area of dentate gyrus. In the CA1 zone of the hippocampus, cell death was scattered along the neurons of the pyramidal-cell band (Fig. 2a), and thus the number of necrotic pyramidal neurons was determined by direct visual counting at six standardized coronal levels. The percent total CA1 necrosis (Fig. 3 b) was obtained by dividing the total number of necrotic cells at all levels by the total number of normal neurons at all levels [19]. 


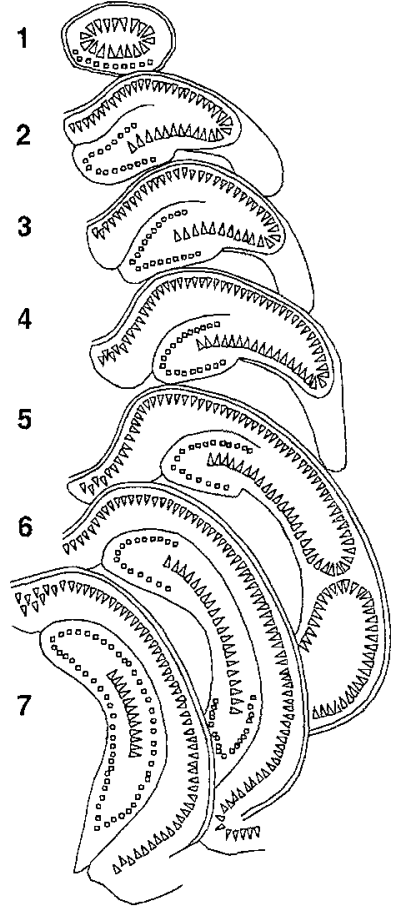

Fig. 1. Diagram of hippocampus showing levels quantified in this study. Dentate cells are represented as small squares, CA1 neurons as small triangles. The seven coronal levels give rise to eight sections through the dentate (two are at level 6) along its septo-temporal axis, and six levels of CA1 (level 1 contains only CA3). Total damage along the entire structure was assessed
In the cerebral cortex, brain damage was quantified by direct visual counting of acidophilic neurons, at coronal level bregma $-1.3 \mathrm{~mm}[24]$. The caudate nucleus was quantified at coronal level bregma $-1.3 \mathrm{~mm}$ [24] by counting the number of necrotic neurons in two 640 - $\mu$ m diameter microscopic fields in the dorsolateral caudate, the area most severely damaged in hypoglycaemia [25].

\section{Statistical analysis}

Mortality was compared between the four groups using the chi-square test. Physiologic parameters between the groups were compared using one-way analysis of variance (ANOVA), followed by the post hoc Scheffé's test for specific intergroup comparisons. The number of necrotic neurons in the cerebral cortex was also analysed during one-way ANOVA and Scheffés test. The percent neuronal death in the caudate nucleus, hippocampal CA1 zone, and dentate gyrus the percentages were subjected to the arcsine transformation, prior to one-way ANOVA and Scheffé's test [26].

\section{Results}

Clinically, the animals treated with nimodipine fared worse than the animals treated with saline and with vehicle. Mortality was $14 \%$ in the saline-treated group, $14 \%$ in the vehicle-treated group, but increased significantly $(p<0.05)$ to 55 and $44 \%$, respectively, in the low-dose and high-dose nimodipine groups. Mortality in all animals was due to cardiorespiratory arrest following a period of sluggish behaviour. Animals treated with nimodipine also appeared more sluggish and less vigorous on recovery.
High-dose nimodipine immediately reduced the blood pressure to $75 \mathrm{~mm} \mathrm{Hg}$ and inhibited the subsequent hypoglycaemia-induced rise in blood pressure which otherwise occurs (usually to $130-140 \mathrm{~mm} \mathrm{Hg}$, Table 1), beginning at the stage of $\delta$-wave $(1-4 \mathrm{~Hz})$ EEG slowing. Mean arterial blood pressure for lowdose nimodipine animals was normal for the rat $(97 \mathrm{~mm} \mathrm{Hg})$. There were no other differences between the groups with respect to physiologic parameters.

In the dentate gyrus (Fig. $3 \mathrm{a}$ ) both doses of nimodipine caused an increase in neuronal necrosis from roughly 15 to $25 \%(p<0.05)$. In the CA1 pyramidal cells (Fig. 3 b) of the hippocampus, a detrimental effect was seen with nimodipine increasing necrosis from $\approx 2 \%$ to $22-23 \%$. In the CA1 zone, a similar effect was seen with the vehicle. The number of necrotic neurons in the cerebral cortex was different only in the high-dose nimodipine group (Fig. $3 \mathrm{c}$ ). Nimodipine also caused an increase in neuronal necrosis in the striatum (Fig. $3 \mathrm{~d}$ ) where a detrimental effect was seen with the vehicle in this brain region.

\section{Discussion}

The findings of this study demonstrate that nimodipine was not beneficial in ameliorating either the clinical or pathologic features of hypoglycaemic brain damage. In fact, nimodipine was detrimental to both clinical survival and to neuronal necrosis. The vehicle also had some effect, a phenomenon reported previously [27], possibly related to the effects of ethanol itself in increasing central dihydropyridine binding [28-30] and thereby calcium-mediated effects. Nimodipine is pharmacokinetically similar to other dihydropyridines such as nifedipine or nicardipine, [31] and has a similar action to other dihydropyridines in blocking L-type neuronal calcium channels [32-34].

The present findings in hypoglycaemia are in contrast with a beneficial effect of nimodipine in reducing brain damage in experimental ischaemia, which has been demonstrated by several groups [13-15]. One possible reason for this difference in hypoglycaemia vs ischaemia is the alkalosis seen during hypoglycaemia [35], which contrasts with the acidosis in the ischaemia [16]. Nimodipine has been shown to reduce the cerebral acidosis in ischaemia [16], perhaps by secondarily influencing the $\mathrm{H}^{+}-\mathrm{Ca}^{2+}$ exchanger. Hydrogen ions influence calcium transport into mitochondria [36] as well as cytosol. Both cellular calcium and proton overload occur in ischaemia, and the amelioration of calcium influx would be expected to reduce ischaemic acidosis, as has been demonstrated [16]. Hypoglycaemia, in contrast, causes a shortage of $\mathrm{H}^{+}$ions due to both ammonia production and a shortage of lactic acid (due to reduced glycolysis). 


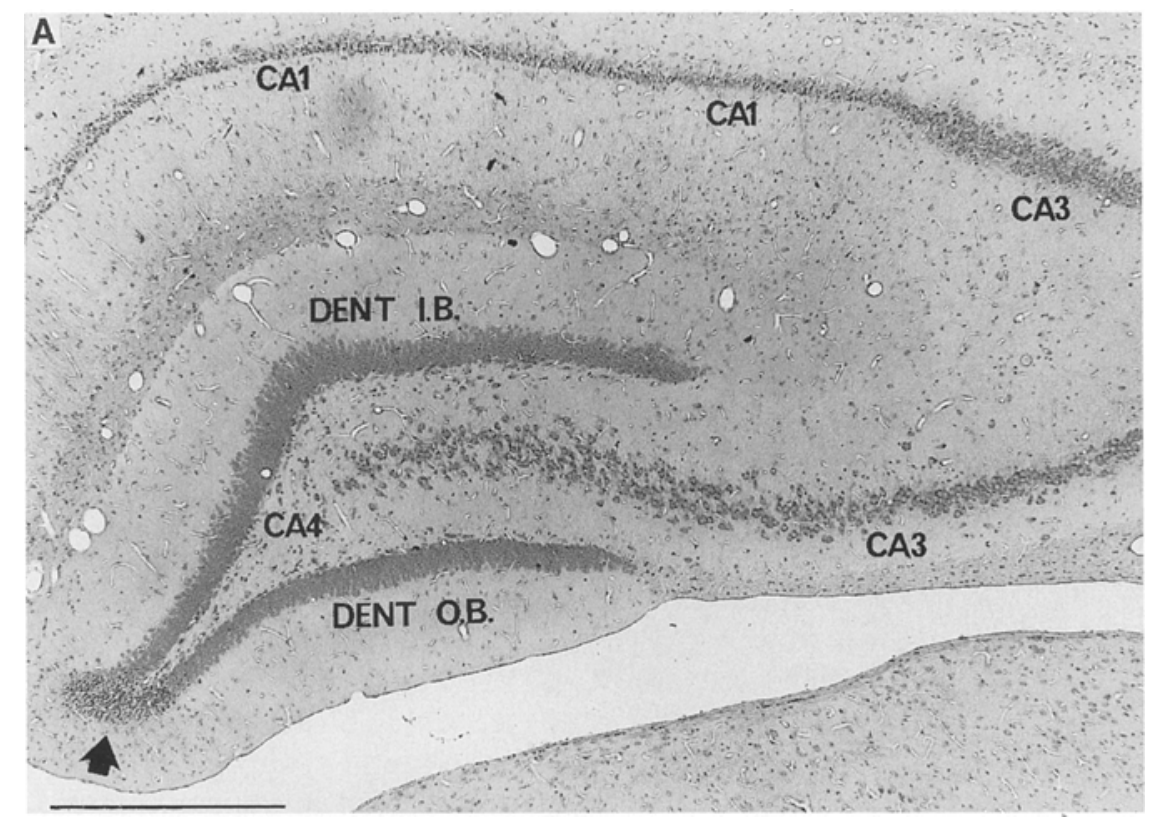

Fig. 2. A. Hippocampus in hypoglycaemic brain damage, showing the various zones of the hippocampus, or cornu ammonis, which are termed CA1, CA3 and CA4. Also shown are the dentate gyrus, with both its inner blade (DENT I.B.) and outer blade (DENT O.B.). Necrotic neurons are seen in a geographic area at the crest of the dentate gyrus (arrow). Individual necrotic neurons are also seen scattered along the CA1-cell band above, and appear dark and punctate due to intense acidophilia in this photomicrograph. CA 3 and CA4 cells are normal.

Bar $=500 \mu \mathrm{m}$. B. Necrosis in the dentate gyrus was quantitated by digitizing the image, measuring the area of necrosis at the crest of the dentate, and dividing by the total area of the inner and outer blade of the dentate (outlined in white) yielding percent dentate necrosis. The cursor is in the CA4 zone of the hippocampus (A).

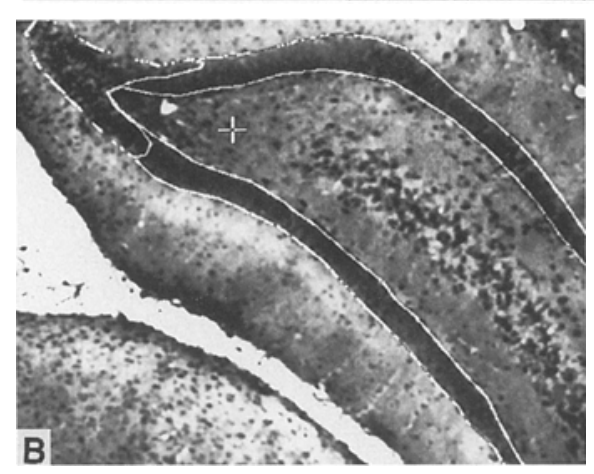

An intracellular alkalosis results [36], the cell consequently having few protons to exchange for calcium. Thus, although calcium falls reversibly in the brain extracellular space [37], probably due to NMDA-receptor-mediated $\mathrm{Ca}^{++}$entry into cells $[8,38,39]$, calcium does not accumulate in central nervous system tissue in hypoglycaemia $[11,17,40]$. These considerations may explain the different effect of voltage-sensitive calcium antagonists in hypoglycaemic brain damage, compared with the beneficial effects seen in brain ischaemia.

The detrimental effect of nimodipine seen in this study cannot easily be ascribed to the hypotension induced by the drug; the effect of more severe hypotension, and energy failure, has been studied in this model of hypoglycaemia [41]. The results showed that hypotension during hypoglycaemia causes no increase in quantitated neuronal necrosis in any brain region, even when the blood pressure was lowered to $60 \mathrm{~mm} \mathrm{Hg}$ [41]. This mean arterial blood pressure is still lower than the $75 \mathrm{~mm} \mathrm{Hg}$ caused by the highdose nimodipine infusion, and thus the exacerbation of hypoglycaemic brain damage caused by nimodipine is unlikely to be due to lowered blood pressure. Hypotension also cannot explain the detrimental ef- fect of the vehicle, since no hypotension was seen. Lastly, the patterns of hypoglycaemic and ischaemic brain damage are easily distinguished in the rat [17], and there was no tendency for the hypoglycaemic pattern to resemble the ischaemic pattern in the nimodipine-treated group. We conclude that in the present study it was unlikely that hypotension accounted for the more severe neuronal necrosis seen with nimodipine.

One possible mechanism by which nimodipine could be detrimental in hypoglycaemia is by causing a superimposed impairment of cellular glucose metabolism in cells already compromised by lack of glucose availability. For example, forebrain slice cultures exposed to $0 \%$ oxygen have a reduced capacity for converting glucose to acetylcholine following the addition of the dihydropyridine calcium antagonists nimodipine and nifedipine [42]. Nimodipine and nifedipine do not block neuronal necrosis in cell culture due to glucose and oxygen deprivation [43]. Indeed, in vitro results suggest that L-type calcium channels (i.e. those blocked by dihydropyridines) do not play a role in glucose deprivation neuronal injury [44]. This is in keeping with the negative in vivo results of Ohta et al. [45] using dihydropyridine in hypoglycaemic brain damage.

Another possible explanation for the present results is a detrimental effect of low intracellular calcium caused by nimodipine. It is clear that, if prolonged, low intracellular calcium levels can be detrimental to neuronal survival [46], but nimodipine does not seem to alter intracellular calcium levels [47]. Nevertheless, dihydropyridine-sensitive $\mathrm{Ca}^{2+}$ channels may play a role in intracellular calcium regulation.

From a clinical point of view, the present results should not be overinterpreted to proscribe the use of 

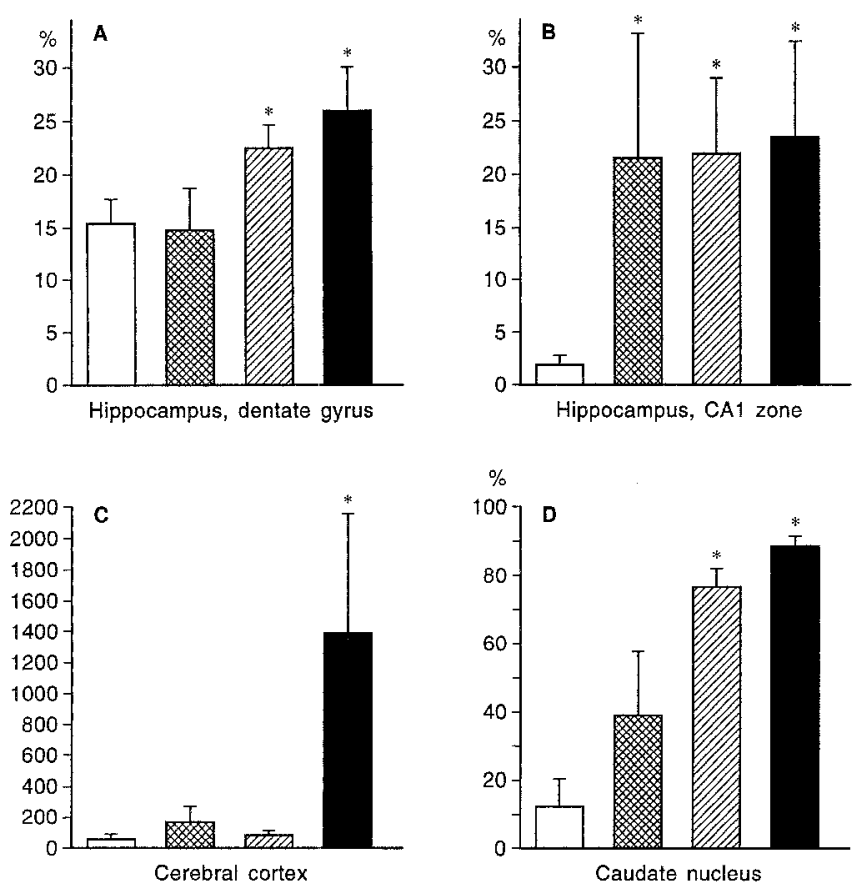

Fig.3. A. Percent necrosis of dentate gyrus, measured as described in Figure 2. Nimopidine caused exacerbation of necrosis of dentate neurons in a dose-dependent manner. B. CA1 pyramidal neurons were counted, and necrosis, expressed as percentage of total neuron counts, was worse in treated groups and in the animals receiving vehicle. C. Number of necrotic neurons in an entire section of neocortex at coronal level breg$\mathrm{ma}-0.6 \mathrm{~mm}$. Neocortical neuronal necrosis is enhanced only by high-dose nimodipine. D. Striatal necrosis, expressed as a percent of the total neuronal count in a $630-\mu \mathrm{m}^{2}$ area of the dorsolateral caudate nucleus, is exacerbated significantly by nimodipine and insignificantly by the vehicle. ${ }^{*} p<0.05$. All results are mean $\pm \mathrm{SEM} . \mathbf{E}, 1.5 \mu \mathrm{g} \cdot \mathrm{kg}^{-1} \cdot \mathrm{min}^{-1}$ nimodipine;

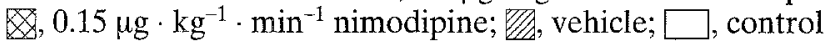

potentially useful dihydropyridines such as nimodipine or isradipine, in treating hypertension [48] or nimodipine in treating diabetic neuropathy [4]. Without hypoglycaemic coma, a necessary prerequisite for hypoglycaemic brain damage, no neuronal damage is incurred in the brain at such stages of hypogly- caemia, even with stupor and $\delta$ wave EEG slowing [19]. Also, the doses of nimodipine used in humans are lower than those used in the present study, and the drug is given orally, not intravenously in humans. Nevertheless, the present findings suggest the need for additional experiments in hypoglycaemic brain damage using doses and routes of administration comparable to those used in humans.

Acknowledgements. The authors wish to thank Ms. Y. Tang for technical assistance. This research was supported by a grant from the Canadian Diabetes Association. Nimodipine was a gift from Miles Pharmaceuticals. L. G. A. is the recipient of an AHFMR studentship, and R.N.A. is the recipient of an AHFMR scholarship.

\section{References}

1. The Diabetes Control and Complications Trial Research Group (1993) The effect of intensive treatment of diabetes on the development and progression of long-term complications in insulin-dependent diabetes mellitus. $\mathrm{N}$ Engl $\mathrm{J}$ Med 329: 977-986

2. Chan JC, Cockram CS, Nicholls MG, Cheung CK, Swaminathan R (1992) Comparison of enalapril and nifedipine in treating non-insulin dependent diabetes associated with hypertension: one year analysis. BMJ 305: 981-985

3. Gomis R, Vidal J, Novials A, Coves MJ (1993) Effects of isradipine and nifedipine retard in hypertensive patients with type II diabetes mellitus. Am J Hypertension 6: S102-S103

4. Kappelle AC, Biessels G, Bravenboer B et al. (1994) Beneficial effect of the $\mathrm{Ca}^{2+}$ antagonist, nimodipine, on existing diabetic neuropathy in the $\mathrm{BB} / \mathrm{W}$ or rat. $\mathrm{Br} \mathrm{J}$ Pharmacol 111: $887-893$

5. Sandberg M, Butcher SP, Hagberg H (1986) Extracellular overflow of neuroactive amino acids during severe insulininduced hypoglycemia: in vivo dialysis of the rat hippocampus. J Neurochem 47:178-184

6. Westerberg E, Kehr J, Ungerstedt U, Wieloch T (1988) The NMDA-antagonist MK-801 reduces extracellular amino acid levels during hypoglycemia and prevents striatal damage. Neurosci Res Comm 3: 151-158

7. Wieloch T (1985) Hypoglycemia-induced neuronal damage prevented by an $\mathrm{N}$-methyl-D-aspartate antagonist. Science 230: $681-683$

Table 1. Physiological parameters and mortality of animals studied

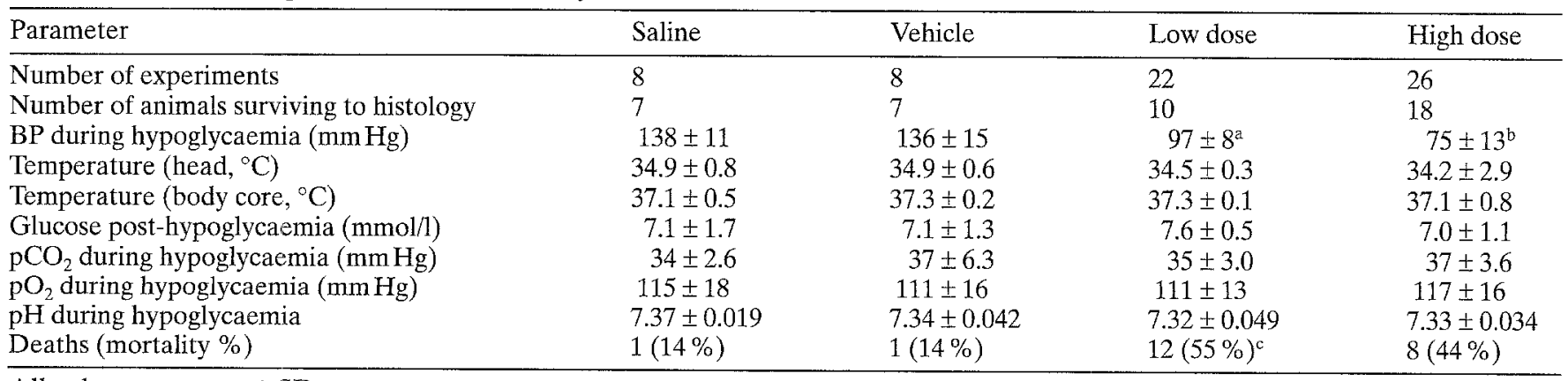

All values are mean $\pm \mathrm{SD}$

${ }^{a}$ Lower than both saline- and vehicle-treated control groups $(p<0.001)$

${ }^{b}$ Lower than both saline- and vehicle-treated control groups $(p<0.001)$, and low-dose nimodipine group $(p<0.005)$

${ }^{\mathrm{c}}$ Mortality higher than saline and vehicle control groups $(p<0.005)$ 
8. Papagapiou MP, Auer RN (1990) Regional neuroprotective effects of the NMDA receptor antagonist MK-801 (dizocilpine) in hypoglycemic brain damage. J Cereb Blood Flow Metab 10: 270-276

9. Auer RN, Hugh J, Cosgrove E, Curry B (1989) Neuropathologic findings in three cases of profound hypoglycemia. Clin Neuropathol 8: 63-68

10. Kalimo H, Olsson Y (1980) Effect of severe hypoglycemia on the human brain. Acta Neurol Scand 62: 345-356

11. Auer RN (1986) Hypoglycemic brain damage. Stroke 17: 488-496

12. Deshpande JK, Wieloch T (1986) Flunarizine, a calcium entry blocker, ameliorates ischemic brain damage in the rat. Anesthesiology 64: 215-224

13. Germano IM, Bartkowski HM, Cassel ME, Pitts LH (1987) The therapeutic value of nimodipine in experimental focal cerebral ischemia. Neurological outcome and histopathological findings. J Neurosurg 67: 81-87

14. Jacewicz M, Brint S, Tanabe J, Pulsinelli W (1990) Continuous nimodipine treatment attenuates cortical infarction in rats subjected to 24 hours of focal ischemia. J Cereb Blood Flow Metab 10: 89-96

15. Mohamed AA, Gotoh O, Graham DI et al. (1985) Effect of pretreatment with the calcium antagonist nimodipine on local cerebral blood flow and histopathology after middle cerebral artery occlusion. Ann Neurol 18: 705-711

16. Hakim AM (1986) Cerebral acidosis in focal ischemia: II. Nimodipine and verapamil normalize cerebral $\mathrm{pH}$ following middle cerebral artery occlusion in the rat. J Cereb Blood Flow Metab 6: 676-683

17. Auer RN, Siesjö BK (1988) Biological differences between ischemia, hypoglycemia, and epilepsy. Ann Neurol 24: 699_ 707

18. Langley MS, Sorkin EM (1989) Nimodipine. A review of its pharmacodynamic and pharmacokinetic properties, and therapeutic potential in cerebrovascular disease. Drugs 37: 669-699

19. Auer RN, Olsson Y, Siesjö BK (1984) Hypoglycemic brain injury in the rat. Correlation of density of brain damage with the EEG isoelectric time: a quantitative study. Diabetes 33: 1090-1098

20. Abdul-Rahman A, Agardh C-D, Siesjö BK (1980) Local cerebral blood flow in the rat during severe hypoglycemia and in the recovery period following glucose injection. Acta Physiol Scand 109: 307-314

21. Auer RN, Kalimo H, Olsson Y, Siesjö BK (1985) The temporal evolution of hypoglycemic brain damage. I. Light and electron microscopic findings in the rat cerebral cortex. Acta Neuropathol (Berl) 67: 13-24

22. Auer RN, Jensen ML, Whishaw IQ (1989) Neurobehavioural deficit due to ischemic brain damage limited to half of the CA1 sector of the hippocampus. J Neurosci 9: 1641-1647

23. Auer RN, Kalimo H, Olsson Y, Wieloch T (1985) The dentate gyrus in hypoglycemia. Pathology implicating excitotoxin-mediated neuronal necrosis. Acta Neuropathol (Berl) 67: 279-288

24. Paxinos G, Watson C (1982) The rat brain in stereotaxic coordinates. Academic Press, Sydney New York London

25. Auer RN, Wieloch T, Olsson Y, Siesjö BK (1984) The distribution of hypoglycemic brain damage. Acta Neuropathol (Berl) 64: 177-191

26. Sokal RR, Rohlf FJ (1981) Biometry. The principles and practice of statistics in biological research. W. H. Freeman and Company, New York

27. Auer LM, Mokry M (1986) Effect of topical nimodipine versus its ethanol-containing vehicle on cat pial arteries. Stroke 17: 225-228
28. Woodward JJ, Machu T, Leslie SW (1990) Chronic ethanol treatment alters omega-conotoxin and Bay K 8644 sensitive calcium channels in rat striatal synaptosomes. Alcohol 7: 279-284

29. Brennan CH, Crabbe J, Littleton JM (1990) Genetic regulation of dihydropyridine-sensitive calcium channels in brain may determine susceptibility to physical dependence on alcohol. Neuropharmacology 29: 429-432

30. Whittington MA, Dolin SJ, Patch TL, Siarey RJ, Butterworth AR, Little HJ (1991) Chronic dihydropyridine treatment can reverse the behavioural consequences of and prevent adaptations to, chronic ethanol treatment. $\mathrm{Br} \mathrm{J}$ Pharmacol 103: 1669-1676

31. Abernethy DR, Schwartz JB (1988) Pharmacokinetics of calcium antagonists under development. Clin Pharmacokinet 15: 1-14

32. Miller RJ (1987) Multiple calcium channels and neuronal function. Science 235: 46-52

33. Wong MCW, Haley EC Jr (1990) Calcium antagonists: stroke therapy coming of age. Stroke 21: 494-501

34. Sauter A, Rudin M (1991) Prevention of stroke and brain damage with calcium antagonists in animals. Am $J$ Hypertens 4: 121S-127S

35. Pelligrino D, Siesjö BK (1981) Regulation of extra- and intracellular $\mathrm{pH}$ in the brain in severe hypoglycemia. J Cereb Blood Flow Metab 1: 85-96

36. Studer RK, Borle AB (1980) The effects of hydrogen ions on the kinetics of calcium transport by rat kidney mitochondria. Arch Biochem Biophys 203: 707-718

37. Kristián T, Gidö G, Siesjö BK (1993) Brain calcium metabolism in hypoglycemic coma. J Cereb Blood Flow Metab 13: 955-961

38. Monyer H, Goldberg MP, Choi DW (1989) Glucose deprivation neuronal injury in cortical culture. Brain Res 483: $347-354$

39. Nellgård B, Wieloch $\mathrm{T}$ (1992) Cerebral protection by AMPA- and NMDA-receptor antagonists administered after severe insulin-induced hypoglycemia. Exp Brain Res 92: 259-266

40. Siesjö BK, Deshpande JK (1987) Electrolyte shifts between brain and plasma in hypoglycemic coma. J Cereb Blood Flow Metab 7: 789-793

41. Auer RN, Hall P, Ingvar M, Siesjö BK (1986) Hypotension as a complication of hypoglycemia leads to enhanced energy failure but no increase in neuronal necrosis. Stroke 17: $442-449$

42. Gibson GE, Mykytyn V (1988) An in vitro model of anoxicinduced damage in mouse brain. Neurochem Res 13:9-20

43. Goldberg MP, Choi DW (1993) Combined oxygen and glucose deprivation in cortical cell culture: calcium-dependent and calcium-independent mechanisms of neuronal injury. $\mathbf{J}$ Neurosci 13: 3510-3524

44. Cheng B, Mattson MP (1992) IGF-I and IGF-II protect cultured hippocampal and septal neurons against calcium-mediated hypoglycemic damage. I Neurosci 12: 1558-1566

45. Ohta S, Smith M-L, Siesjö BK (1991) The effect of a dihydropyridine calcium antagonist (isradipine) on selective neuronal necrosis. J Neurol Sci 103: 109-115

46. Dubinsky JM (1993) Effects of calcium chelators on intracellular calcium and excitotoxicity. Neurosci Lett 150: 129-132

47. Tymianski M, Charlton MP, Carlen PL, Tator CH (1993) Source specificity of early calcium neurotoxicity in cultured embryonic spinal neurons. J Neurosci 13: 2085-2104

48. Hansson L (1990) Isradipine in hypertension. Drugs 40 [Suppl 2]: 10-14 